\title{
Haloperidol Differentially Modulates Prepulse Inhibition and P50 Suppression in Healthy Humans Stratified for Low and High Gating Levels
}

\author{
Philipp A Csomor ${ }^{1,2}$, Renée R Stadler ${ }^{1,2}$, Joram Feldon ${ }^{2}$, Benjamin K $\mathrm{Yee}^{2}$, Mark A Geyer ${ }^{3}$ and \\ Franz X Vollenweider*, I \\ 'University Hospital of Psychiatry Zurich, Experimental Psychopathology and Brain Imaging, Zurich, Switzerland; '2Laboratory of Behavioural \\ Neurobiology, ETH Zurich, Schwerzenbach, Switzerland; ${ }^{3}$ Department of Psychiatry, University of California at San Diego, La Jolla, CA, USA
}

\begin{abstract}
Schizophrenia patients exhibit deficits in sensory gating as indexed by reduced prepulse inhibition (PPI) and P50 suppression, which have been linked to psychotic symptom formation and cognitive deficits. Although recent evidence suggests that atypical antipsychotics might be superior over typical antipsychotics in reversing PPI and P50 suppression deficits not only in schizophrenia patients, but also in healthy volunteers exhibiting low levels of PPI, the impact of typical antipsychotics on these gating measures is less clear. To explore the impact of the dopamine $\mathrm{D}_{2}$-like receptor system on gating and cognition, the acute effects of haloperidol on PPI, P50 suppression, and cognition were assessed in 26 healthy male volunteers split into subgroups having low vs high PPI or P50 suppression levels using a placebocontrolled within-subject design. Haloperidol failed to increase PPI in subjects exhibiting low levels of PPI, but attenuated PPI in those subjects with high sensorimotor gating levels. Furthermore, haloperidol increased P50 suppression in subjects exhibiting low P50 gating and disrupted P50 suppression in individuals expressing high P50 gating levels. Independently of drug condition, high PPI levels were associated with superior strategy formation and execution times in a subset of cognitive tests. Moreover, haloperidol impaired spatial working memory performance and planning ability. These findings suggest that dopamine $D_{2}$-like receptors are critically involved in the modulation of P50 suppression in healthy volunteers, and to a lesser extent also in PPI among subjects expressing high sensorimotor gating levels. Furthermore, the results suggest a relation between sensorimotor gating and working memory performance.

Neuropsychopharmacology (2008) 33, 497-5I2; doi:I0.1038/sj.npp. I301421; published online 25 April 2007
\end{abstract}

Keywords: haloperidol; prepulse inhibition; P50 suppression; sensorimotor gating; working memory; human

\section{INTRODUCTION}

Deficits in early information processing potentially leading to sensory overload have been considered a central feature of schizophrenia. It has been postulated that impaired cognition and positive symptoms of schizophrenia are related to deficient inhibition of early information processing (for a review see Braff et al, 2001). Two paradigms designed to assess central inhibition or gating are prepulse inhibition (PPI) of the acoustic startle response and suppression of the P50 event-related potential in a condition-test paradigm. PPI refers to the attenuation of the reflexive startle reaction elicited by an intense pulse stimulus when its presentation is shortly preceded

* Correspondence: Dr FX Vollenweider, University Hospital of Psychiatry Zurich, Lenggstrasse 31, CH-8029 Zurich, Switzerland, Tel: + 4 I 44 3822604, Fax: + 4 I 44 3843396, E-mail: vollen@bli.unizh.ch Received I4 December 2006; revised 12 March 2007; accepted 13 March 2007
$(30-300 \mathrm{~ms})$ by a weak prepulse stimulus (Hoffman and Ison, 1980; Graham, 1975). According to the 'protective hypothesis' of Graham (1975, 1980, 1992), the inhibitory effect of the prepulse upon subsequent pulse processing reflects the protection of the ongoing processing of the antecedent prepulse against interference by the succeeding pulse. In practice, the magnitude of PPI is measured by the diminution of the startle response to the pulse stimulus due to the antecedent prepulse stimulus. The expression of PPI therefore represents an interplay of prepulse and pulse processing. This phenomenon is commonly considered as a form of sensorimotor gating, and can be readily demonstrated across species, from mollusc (Frost et al, 2003) to higher mammals including human (Braff et al, 2001).

Similarly, in the P50 suppression paradigm two auditory stimuli are presented in succession at an interstimulus interval typically of $500 \mathrm{~ms}$. The first stimulus (conditioning stimulus) not only produces an auditory evoked potential (AEP) approximately $50 \mathrm{~ms}$ after stimulation (P50 wave), but also activates gating processes, resulting in a suppression 
of the P50 AEP to the second stimulus (test stimulus). A number of studies have demonstrated that patients with schizophrenia exhibit deficits in both PPI (Braff et al, 1978, 2001) and P50 suppression (Adler et al, 1982; Light and Braff, 1999; Cadenhead, 2002). In addition, low PPI and P50 suppression levels have also been found in individuals with schizotypal personality disorder (Cadenhead et al, 1993, 2000; Cadenhead, 2002) and in unaffected relatives of patients with schizophrenia (Kumari et al, 2005; Clementz et al, 1998b). Thus, it has been proposed that PPI and P50 suppression are endophenotypic markers for schizophrenia spectrum disorders (Cadenhead et al, 2002; Braff and Light, 2005). As such, these gating measures provide a unique opportunity to characterize the neurochemical basis of information processing deficits and the impact of antipsychotic treatments (Geyer et al, 2001). Indeed, it has recently been proposed that atypical antipsychotics might be superior over typical antipsychotics in normalizing PPI and P50 suppression deficits in schizophrenia patients (Kumari and Sharma, 2002; Adler et al, 2004; Becker et al, 2004; Light et al, 2000). Nevertheless, a number of studies showed that PPI and P50 suppression are not associated in either healthy volunteers (Schwarzkopf et al, 1993; Oranje et al, 2006; Brenner et al, 2004; Light and Braff, 2001) or schizophrenia patients (Braff et al, 2006). Some relationship of P50 suppression to PPI was noted during the early part of the test session, when the process of habituation of the startle reflex is active (Oranje et al, 1999). Similarly, PPI and AEP gating in rats are not correlated (Ellenbroek et al, 1999) and the two phenomena exhibit differential sensitivities to drug treatments (de Bruin et al, 1999). These results derived from both humans and rodents suggest that different neural mechanisms underlie PPI and P50 suppression.

Results of a number of cross-sectional studies suggest that patients treated for schizophrenia with atypical antipsychotics have similar PPI values as normal controls (Kumari et al, 1999, 2000, 2002; Leumann et al, 2002; Oranje et al, 2002b), whereas those treated with typical antipsychotics exhibited less PPI than the control subjects (Grillon et al, 1992; Kumari et al, 1999; Oranje et al, 2002b). However, another study failed to replicate this distinction, finding that typical and atypical medications were equipotent in reversing the PPI deficit in schizophrenia patients (Quednow et al, 2005). On the other hand, several studies have failed to show PPI-enhancing effects of either typical or atypical medication in schizophrenia patients (Duncan et al, 2003a, b; Perry et al, 2002; Mackeprang et al, 2002), even though Duncan et al (2003b) found an improvement of clinical symptoms with atypical medication. In contrast to these negative findings, a recent study showed that an enhancement of PPI is associated with symptom reduction in patients treated for schizophrenia with either typical or atypical antipsychotic treatments (Meincke et al, 2004). Although it appears that atypical antipsychotics may be superior in normalizing PPI, the literature to date is inconclusive regarding the impact of antipsychotic medication on PPI. Consequently, the impact of antipsychotic medication on PPI in schizophrenia patients remains uncertain.

To explore further the effect of antipsychotic medication on PPI, a number of recent studies have investigated the possible differential effects of typical and atypical antipsychotics on PPI in healthy humans, rather than in patients. The use of normal healthy subjects with or without pharmacological challenge has the potential to overcome the confounding effects of previous medication exposure in patient populations. The wide range in severity of psychopathology and the generally nonrandom allocation of patients to treatment regimens (Hamm et al, 2001; Kumari and Sharma, 2002) can be a considerable source of variability in results between studies. So far none of the studies investigating whether atypical antipsychotics increase PPI in normal subjects exhibiting a wide range of PPI yielded positive results (Graham et al, 2001, 2004; Barrett et al, 2004). However, two recent studies demonstrated that atypical antipsychotics such as clozapine or quetiapine increase PPI in clinically unaffected healthy subjects with low baseline PPI (Vollenweider et al, 2006; Swerdlow et al, 2006). Specifically, we have found that the mixed $5-\mathrm{HT}_{2} / \mathrm{D}_{2}$ receptor antagonist clozapine increased PPI in those normal subjects with a characteristically low PPI level at stimulus onset asynchrony (SOA) of 60 and $120 \mathrm{~ms}$ (Vollenweider et al, 2006), whereas Swerdlow et al (2006) reported that quetiapine increased PPI at relatively brief SOAs of 20 and $30 \mathrm{~ms}$ in a similar group of healthy subjects with low PPI. On the other hand, two studies investigating the effects of the typical antipsychotic haloperidol found a disruption of PPI (Abduljawad et al, 1998; Oranje et al, 2004b) in healthy subjects, although the former study could not be replicated by that group (Abduljawad et al, 1999). Furthermore, one study (Kumari et al, 1998) reported that haloperidol disrupted PPI in normal smoking subjects but had no such effect in nonsmoking subjects. In contrast to these findings, a number of other studies reported no effect of haloperidol on PPI in healthy volunteers (Kumari et al, 1998; Abduljawad et al, 1999; Liechti et al, 2001; Graham et al, 2001, 2002, 2004). Similarly, chlorpromazine, a potent $D_{2}$ receptor antagonist, was also found to have no effect on PPI (Barrett et al, 2004) in healthy volunteers. Taken together, these findings suggest that $D_{2}$ receptor antagonists are without effect on, or tend to attenuate, PPI in normal subjects.

The influence of antipsychotic medication on P50 suppression has been investigated in several patient studies. Schizophrenia patients treated with atypical antipsychotics had superior P50 suppression to those treated with conventional antipsychotic medication (Light et al, 2000; Becker et al, 2004; Adler et al, 2004). Especially patients receiving the atypical antipsychotic clozapine exhibited P50 suppression in the range of normal controls (Becker et al, 2004; Adler et al, 2004). In another study, Nagamoto et al (1996) showed that patients who were refractory to conventional neuroleptics, but were clinically responsive to clozapine, also exhibited enhanced P50 suppression levels. On the other hand, Arango et al (2003) could not show any difference in P50 suppression in schizophrenia patients who were treated with either olanzapine or haloperidol for 3 months. In contrast to the many studies exploring the effect of antipsychotic medication on P50 suppression in schizophrenia patients, few studies have investigated the effects of such treatment in healthy volunteers. Oranje et al (2002a) found that a combination of haloperidol and ketamine disrupted P50 suppression in healthy volunteers, whereas the administration of ketamine alone had no effect on P50 gating. 
In addition to the well-documented deficits in PPI and P50 suppression, the occurrence of impaired cognitive performance, especially working memory, is a robust finding in schizophrenia patients (Hutton et al, 1998; Weickert et al, 2000; Badcock et al, 2005). Moreover, it has recently been demonstrated that those healthy human volunteers exhibiting low levels of PPI also show impaired performance in specific cognitive tasks relying on prefrontal cortical functioning (Giakoumaki et al, 2006; Bitsios et al, 2006). These authors concluded that superior ability in cognitive performance is related to more efficient early information processing.

Based upon the above review of available literature, we hypothesized that haloperidol would not influence gating in those normal subjects with relatively high PPI/P50 suppression levels, but would increase PPI and/or P50 suppression in those normal subjects with low gating performance at baseline. Furthermore, we predicted that sensory and/or sensorimotor gating levels correlate with cognitive performance, as reported previously (Giakoumaki et al, 2006; Bitsios et al, 2006), and that cognitive performance is influenced by the administration of haloperidol. To test these hypotheses, we measured the effects of acute treatment with the dopamine $\mathrm{D}_{2}$ receptor antagonist haloperidol on PPI and P50 suppression in a group of healthy volunteers, who were stratified according to low or high placebo gating levels, based upon our study design for investigating the effect of clozapine on PPI in normal volunteers (Vollenweider et al, 2006). A subset of tests from the Cambridge Neuropsychological Test Automated Battery (CANTAB) was used to assess attentional set shifting, working memory, and executive functioning and their relationship to haloperidol treatment and sensory gating.

\section{MATERIALS AND METHODS}

\section{Subjects}

Thirty-four healthy male volunteers were recruited by advertisement. Owing to the occurrence of gender differences in PPI (Swerdlow et al, 1996), only male subjects were included. The study was approved by the ethics committee of Zurich canton and Swissmedic. All subjects gave their informed written consent, were without a history of mental (according to DSM IV, axis I and II) and neurological disorders, had no history of an axis I disorder amongst their first-degree relatives, and were free of any medication for at least 3 weeks before the experiment. To ascertain the subjects' mental status, all subjects were screened by the DIA-X diagnostic expert system (Wittchen and Pfister, 1997), a semi-structured psychiatric interview. Subjects with personal or family (first-degree relatives) histories of major psychiatric disorders were excluded. Assessment of the use of legal and illegal drugs was done using a structured interview. Furthermore, all the volunteers underwent clinical examination that included electrocardiography and blood analysis. All subjects were instructed to abstain from drinking alcohol for at least $24 \mathrm{~h}$ before each test session, not to drink any caffeine-containing beverages on the day of testing, and to keep their usual smoking habits. Smoking was not allowed from $1 \mathrm{~h}$ before the recording session. From the original 34 subjects agreeing to participate in the study, two were excluded due to declaration of substance abuse, and three were excluded because physical examination indicated a contraindication for taking haloperidol. Additionally, three volunteers withdrew from the study after the first test day. All remaining 26 subjects completed the CANTAB measurement. The PPI data of three subjects were rejected because no distinct startle reaction could be elicited (nonresponders, mean startle amplitude on pulse-alone trials $<10 \mu \mathrm{V}$ in the presentation block relevant for \%PPI calculation) and four subjects declined to continue electrophysiological recordings after completing the PPI assessment, thus resulting in 19 complete datasets (PPI, P50, CANTAB), with only PPI and CANTAB data from four subjects, and only P50 and CANTAB data from three subjects. Hearing was evaluated in all subjects, using a standard computerized whispered voice test (for a review, see Pirozzo et al, 2003). No subjects were excluded due to hearing difficulties. Subject demographics are summarized in Table 1.

\section{Experimental Design}

In a double-blind, placebo-controlled within-subjects design, participants received haloperidol $(2 \mathrm{mg}$ per $70 \mathrm{~kg}$ body weight, dose ranged from 1.8 to $2.7 \mathrm{mg}$ ) or placebo (saline solution) intravenously in a balanced and random sequence, on two experimental days, 7 to 14 days apart. Haloperidol (Haldol) was obtained from Janssen (Janssen-Cilag AG, Zug, Switzerland). On each experimental day, $30 \mathrm{~min}$ after drug administration, subjects underwent the PPI assessment

Table I Demographic Characteristics of the Subjects Stratified into Low and High Sensory Gating Groups

\begin{tabular}{|c|c|c|c|c|c|c|c|c|}
\hline & \multicolumn{2}{|c|}{ Low PPI group $(n=I I)$} & \multicolumn{2}{|c|}{ High PPI group $(n=12)$} & \multicolumn{2}{|c|}{ Low P50 group $(n=I I)$} & \multicolumn{2}{|c|}{ High P50 group $(n=I I)$} \\
\hline & Mean & SE & Mean & SE & Mean & SE & Mean & SE \\
\hline BMI & 22.05 & 0.46 & 22.56 & 0.37 & 22.01 & 0.38 & 22.81 & 0.73 \\
\hline MWT-B $\left.\right|^{a}$ & 113.00 & 3.94 & 119.33 & 3.83 & 115.55 & 4.37 & 116.64 & 4.18 \\
\hline
\end{tabular}

Abbreviations: BMI, body mass index; IQ, intelligence quotient; PPI, prepulse inhibition; SE, standard error.

${ }^{a}$ Verbal IQ, as estimated by the Mehrfachwahl-Wortschatz-Intelligenztest (MWT-B) (Lehrl, 1999).

bess than five cigarettes per day. 
followed by a short break prior to the P50 suppression session. After detaching all electrodes used in the electrophysiological recordings, subjects underwent neuropsychological testing using a subset of CANTAB tests.

\section{PPI and P50 Suppression Session Definition}

The PPI test session was composed of a mixture of pulsealone trials, prepulse-pulse trials and trials in which no discrete stimulus other than the constant background noise was presented (denoted hereafter as 'no-stimulus' or 'NS trials'). All stimuli (background noise, pulses, and prepulses) used in the experiment consisted of broadband white noise. The intensity of the background noise was set at $70 \mathrm{~dB}_{\mathrm{A}}$. Pulse stimulus intensity was set at $115 \mathrm{~dB}_{\mathrm{A}}$ and the prepulse stimulus intensity at $86 \mathrm{~dB}_{\mathrm{A}}$. The stimulus duration was $40 \mathrm{~ms}$ for pulse stimuli and $20 \mathrm{~ms}$ for prepulse stimuli. Rise and fall time of the stimuli were less than $1 \mathrm{~ms}$. The four SOA between the prepulse and pulse stimuli on prepulse-pulse trials were 60,120,240, and $2000 \mathrm{~ms}$ (SOA 60 , SOA 120 , SOA 240 , and SOA 2000). The session began with a 2 min period of acclimatization to the background noise, followed by the presentations of 69 discrete trials according to a variable intertrial interval ranging from 9 to $18 \mathrm{~s}($ mean $=13.7)$. The first and last block consisted of five consecutive pulse-alone trials. The middle block consisted of 60 trials, ie 10 trials of each of the six conditions (pulsealone, prepulse-pulse combinations, and NS trial). The sequence of presentation was pseudo-randomized. The PPI test session lasted approximately $17 \mathrm{~min}$.

The P50 suppression test session was composed of 80 pairs of auditory clicks with a $500 \mathrm{~ms}$ interclick interval presented every $8-12 \mathrm{~s}$ (mean $=9.8)$. Stimuli consisted of $86 \mathrm{~dB}_{\mathrm{A}}$ white noise with a duration of $1 \mathrm{~ms}$. The P50 suppression session lasted for approximately $15 \mathrm{~min}$.

\section{Apparatus, Data Recording and Data Processing}

Electromyographic (EMG) and electroencephalographic (EEG) recordings were performed in the same soundproof EEG room. The subjects were informed that the first experiment (PPI) was intended to investigate simple blink reflexes in the presence of broadband white noise, and the second experiment (P50 suppression) was for the investigation of changes in brain activity upon auditory stimulation. They were informed that the stimuli themselves did not pose any risk to their hearing. Subjects were then asked to sit comfortably in a chair, to relax, and stay awake while looking at a blank wall approximately $2 \mathrm{~m}$ away.

Acoustic stimuli were generated by EMG-SR (San Diego Instruments, San Diego, CA, USA) and presented binaurally through headphones (TDH-39-P, Maico, Minneapolis, MN, USA). EEG recordings were made from 64 scalp locations (10-20 system) using the ActiveTwo system (Biosemi, The Netherlands). The horizontal electroocculogram (EOG) was recorded from electrodes attached on the outer canthus of each eye. Similarly, vertical EOG was recorded from electrodes attached infraorbitally and supraorbitally to the left eye. Additionally, startle reaction was assessed from two electrodes placed below the right eye over the orbicularis oculi muscle. All electrodes were active silver/silver chloride electrodes and the offset of all electrodes was below $25 \mu \mathrm{V}$.
The trigger signal to mark stimulus onset was sent over the parallel port of the stimulus computer to the recording unit. The system recorded continuously over the whole session using a sampling rate of $4096 \mathrm{~Hz}$ for the PPI paradigm and $512 \mathrm{~Hz}$ for the P50 suppression paradigm. Analyzer (Brainvision, Germany) was used to preprocess the recorded data.

For the PPI paradigm, the two electrodes located over the orbicularis oculi muscle were referenced bipolarly, resulting in a single EMG channel. EMG activity was band-pass filtered $(30-500 \mathrm{~Hz})$, downsampled to $1000 \mathrm{~Hz}$ to reduce the amount of data, and then rectified. Segmentation was performed from $50 \mathrm{~ms}$ prior to the onset of the relevant stimulus (the prepulse in prepulse-pulse trials, respectively the pulse in pulse-alone trials) to $2250 \mathrm{~ms}$ after stimulus onset. The segmented data were exported for quantitative analysis. The EMG record of each and every trial was separately scored using the Windows-based software emgBLINK version 1.2 (CST, Switzerland). Before scoring, the EMG was smoothed with a time constant of $5 \mathrm{~ms}$. Baseline amplitude was calculated by the mean response amplitude of the first $50 \mathrm{~ms}$ before any stimulus onset. Stimulus response amplitudes were assessed as peak response minus baseline value of the respective trial. Peak response was defined as the highest reaction in the time window between stimulus onset and $150 \mathrm{~ms}$ after stimulus onset. In pulse-alone trials and prepulse-pulse trials reaction to the pulse was scored. Additionally, in the prepulse-pulse trials with an SOA of 2000 and $240 \mathrm{~ms}$ reaction to the prepulse was scored. Response amplitudes on NS trials were scored as peak response sample between 51 and $201 \mathrm{~ms}$ minus baseline value of the respective trial. Every trial was also examined for sign of spontaneous eyeblinks in the scoring windows, and other possible signs of corrupted EMG signal and if present the trial was excluded.

For the P50 suppression paradigm, data were band-pass filtered $(1.5-70 \mathrm{~Hz}, 50 \mathrm{~Hz}$ notch filter). Independent component analysis was used to remove artifacts due to eye movements and blinks. Then, EEG data were re-referenced to the average of the 64 scalp electrodes (average reference) and segmented from $800 \mathrm{~ms}$ before to $1000 \mathrm{~ms}$ after the first click. The resulting 80 segments were visually screened for any sign of corrupted EEG and, if present, excluded from further processing. The artifact-free segments were then resegmented $50 \mathrm{~ms}$ before click onset to $300 \mathrm{~ms}$ after click onset separately for both stimulus conditions (click 1 and click 2) and then averaged. The P50 component of the AEP was identified and scored as described by Nagamoto et al (1989). The P50 peak was identified as the most positive deflection $40-80 \mathrm{~ms}$ after stimulus presentation. The P50 amplitude was scored as the absolute difference between the P50 peak and the preceding negative trough. Only data from the $\mathrm{Cz}$ location were analyzed where the maximum activity for the P50 AEP was expected (Clementz et al, 1998a).

\section{Assessed Parameters}

For the PPI paradigm the following startle measures were examined: (1) Pulse-alone and prepulse-elicited reaction: The mean startle reactivity elicited by the pulse-alone stimulus in each of the three pulse blocks was calculated for 
each subject. The same was conducted separately in regard to the prepulse in the prepulse-pulse trials (SOA 240 and $2000 \mathrm{~ms}$ ). The mean reactivity score obtained on NS trials was also calculated and included as a control condition. (2) PPI: Percentage PPI (\%PPI) was calculated for each SOA by the formula: (1-(amplitude prepulse-pulse $) /\left(\right.$ amplitude $\left._{\text {pulse-alone(block2) }}\right)$ ) $\times 100 \%$. (3) Habituation: The reduction of the startle amplitudes between the first and last block was calculated according to the formula: (1-(amplitude pulse-alone(block3) $) /$ (amplitude $\left.e_{\text {pulse-alone(block1) }}\right) \times 100 \%$. (4) Sensitization: Percentage scores were calculated for the mean amplitude of trials 2-5 in relation to the first trial according to the formula: (mean amplitude trials $2-5_{5} /$ amplitude $\left._{\text {trial }}{ }_{1}\right) \times$ $100 \%$.

For the P50 suppression, paradigm the following ERP measures were examined: (1) P50 amplitudes: P50 amplitude evoked by the first (s1) and second click stimulus (s2). (2) P50 suppression: Percentage P50 suppression was calculated by the formula: $\left(1-\left(\right.\right.$ amplitude $\left._{\mathrm{s} 2}\right) /\left(\right.$ amplitude $\left.\left._{\mathrm{s} 1}\right)\right) \times 100 \%$.

As summarized briefly below, seven tests of the CANTAB were administered using an IBM-compatible PC with a touch-screen monitor (Elo IntelliTouch). More technical descriptions of the tasks can be found on the Cambridge Cognition's website www.cantab.com. (1) Motor screening: All subjects were introduced to the touch-screen procedure by completing a simple motor screening task consisting of touching the center point of flashing crosses on the screen as soon as possible after its presentation (results not shown). (2) Rapid visual information processing (RVP): This task is a visual continuous performance task using predefined sequences of three digits presented at a rate of 100 per minute so as to assess sustained attention over a period of $4 \mathrm{~min}$. RVP performance was assessed by total correct responses to target sequences (total hits), the sensitivity to detect target sequences ( $\mathrm{A}^{\prime}$ ), and the mean latency to target sequences. (3) Pattern recognition memory (PRM): This task assesses visual recognition memory in a two-choice forced discrimination paradigm. Performance was indexed by the mean latency to the correct answer, and the percentage of correct hits. (4) Stockings of Cambridge (SOC): This test assesses the subject's spatial planning ability, based upon the 'Tower of London' task (Shallice, 1982). The total number of problems solved in the minimum possible number of moves, the number of moves to reach criterion, initial thinking time, and subsequent thinking time were all assessed. (5) Spatial Working Memory (SWM): This is a test of spatial working memory and strategy performance. The subject had to find a blue 'token' in each displayed box, while not returning to boxes in which a blue token had already been found. Performance was indexed by a strategy score, which represents the number of times the subject begins a new search with the same box. A high score represents poor use of this strategy and a low score equates to effective use. Furthermore, the total number of errors and between errors (searching a token in a box where one had already been found) was assessed. (6) Intra/Extradimensional attentional set shifting (ID/ED): This is a test of rule acquisition and reversal, featuring visual discrimination and attentional set shifting, analogous to the Wisconsin Card Sorting Task (Heaton, 1981). Performance was assessed by the number of trials to reach criterion, the total number of errors (adjusted to the number of completed stages), the errors made up to the extradimensional shift (Pre-ED errors) and the errors made at the extradimensional shift stage of the task (EDS errors). (7) Spatial recognition memory (SRM): This task tests visual spatial memory in a two-choice forced discrimination paradigm. Performance was indexed by the mean latency to correct answers, and percent of correct hits of a maximum of 20 .

\section{Statistical Analysis}

All statistical analyses were conducted using the statistical software Statistica 7 for Windows (Statsoft Inc., OK, USA). To test whether haloperidol had a differential effect on subjects with low or high placebo gating measures, subjects were grouped by a median-split procedure into low and high performers. For the PPI paradigm, this median-spilt was based on the results of \%PPI in the SOA 60 placebo condition $\left(\right.$ median $\left._{\mathrm{PPI}}=61.6 \%\right)$. Similarly, for the P50 suppression paradigm the median-split was applied using the \%P50 suppression scores in the placebo condition $\left(\right.$ median $\left._{\mathrm{P} 50}=63.8 \%\right)$. An alternate approach of segregation by mean split $\left(\operatorname{mean}_{\mathrm{PPI}}=63.2 \% ; \operatorname{mean}_{\mathrm{P} 50}=51.0 \%\right)$ was considered, and was found to result in identical PPI grouping, and virtually the same P50 groups, differing only by two subjects. As summarized in Table 1, the low and high PPI and P50 groups did not differ in age, smoking habits, or IQ as measured by the Mehrfachwahl-Wortschatz-Intelligenztest (Lehrl, 1999).

Startle amplitudes were analyzed using repeated measures analysis of variance (ANOVA) with block (1-3) and treatment (placebo $v s$ haloperidol) as within-subject factors and group (low vs high) as between-subject factors. Similarly, \%PPI values were subjected to a $4 \times 2 \times 2$ $(\mathrm{SOA} \times$ treatment $\times$ group) repeated measures ANOVA. Analysis of \%habituation was performed analogously as above, but with treatment as within-subject factor and group as between-subject factor, separately for PPI and P50 groups. A three-way ANOVA (SOA and treatment as repeated measures and group as between-subject factor) for prepulse-elicited reactions was performed including the NS, SOA 240, and SOA 2000 conditions only, since these SOAs allow the use of the same scoring window size $(150 \mathrm{~ms})$ as had been used for the scoring of all the other trial types. Amplitude and latency of the P50 component were likewise analyzed using a three-way ANOVA with the factors stimulus type (conditioning $v$ s test stimulus), group, and treatment. The \%P50 suppression data were analyzed by a $2 \times 2$ (treatment $\times$ group) repeated measures ANOVA.

Potential commonalities between the PPI and P50 suppression paradigm were investigated by Pearson correlations between amplitude and suppression values of the two gating paradigms. Two-way ANOVAs with group and treatment were used to examine the effect of haloperidol on the performance of RVP, PRM, SRM, and ID/ED CANTAB tasks. For the SOC and SWM CANTAB tasks, the additional factor 'difficulty' was introduced. For significant effects, the effect size, expressed as partial eta-squared $\left(\eta_{\mathrm{p}}^{2}\right)$, was also calculated. To assess relationships between gating measures and CANTAB scores, Pearson correlations were calculated. Due to the high number of correlations examined, the 
significance level for Pearson correlations was set to $p<0.0008$. For the other statistical tests the significance level was set to $p<0.05$.

\section{RESULTS}

\section{Prepulse Inhibition Paradigm}

The results are summarized in Table 2. There was no significant difference in startle amplitude between the two groups, nor any change of startle induced by haloperidol. As expected, startle amplitude significantly diminished over the three blocks (main effect of block; $\mathrm{F}(2,42)=31.58$, $p<0.001, \eta_{\mathrm{p}}^{2}=0.60$ ). However, \%habituation and \%sensitization did not differ between the low and high PPI or P50 suppression groups, nor were they influenced by haloperidol.

Due to the median-splitting of subjects into low and high sensorimotor gaters, \%PPI was significantly different between the two groups (main effect of group; $\left.\mathrm{F}(1,21)=7.32, p<0.05, \eta_{\mathrm{p}}^{2}=0.26\right)$. Moreover, there was a significant main effect of SOA $(\mathrm{F}(3,63)=58.12, p<0.001$, $\left.\eta_{\mathrm{p}}^{2}=0.73\right)$ and a significant $\mathrm{SOA} \times$ group interaction $\left(\mathrm{F}(3,63)=4.4, \quad p<0.01, \eta_{\mathrm{p}}^{2}=0.17\right)$. No significant main effect of treatment was found (Figure 1). Results of the ANOVA revealed a nonsignificant treatment $\times$ group interaction $(\mathrm{F}(1,21)=2.85, p=0.11)$. Nevertheless, based on our a priori hypothesis that haloperidol would modulate PPI differentially in subjects exhibiting either low or high baseline PPI levels, two-way ANOVAs restricted to the inhibitory SOAs $(60,120$, and $240 \mathrm{~ms})$ were performed separately for either the low and high PPI groups. Results of these analyses approached statistical significance for main effect of treatment in the high PPI group $(F(1,11)=4.76$, $\left.p=0.05, \eta_{\mathrm{p}}^{2}=0.30\right)$, but not in the low PPI group, indicating a reduction of PPI in the high group upon haloperidol treatment. Furthermore, there was a significant main effect for SOA in both groups (high group: $\mathrm{F}(2,22)=19.83$, $p<0.001, \eta_{\mathrm{p}}^{2}=0.64$; low group: $\mathrm{F}(2,20)=8.65, p<0.01$, $\left.\eta_{\mathrm{p}}^{2}=0.46\right)$. For the examination of the impact of test order (active drug test day $1 v s$ test day 2), repeated measures ANOVA with the factors group, SOA, treatment, and test order were performed. This analysis revealed neither a significant main effect of test order nor any interactions between test order and the other factors. Therefore, to optimize the statistical power, the factor 'test order' was dropped from the final analysis. Pearson correlations revealed no relationship between the absolute dose of haloperidol administered and change in \%PPI upon treatment for any SOA.

Analysis of prepulse-elicited reaction revealed no significant main effect of treatment, and no effect of group, but did reveal a significant main effect of trial type $\left(\mathrm{F}(2,42)=4.99, p<0.05, \eta_{\mathrm{p}}^{2}=0.19\right)$. Fisher's least significant difference (LSD) post hoc testing on SOA showed that the effect of trial type is a consequence of the two prepulse conditions being different from the NS condition $\left(p_{\text {post hoc }}<0.05\right.$ for SOA 240 and $p_{\text {post hoc }}<0.01$ for SOA $2000)$, while being similar to each other $(p=0.93)$, indicating that the prepulse stimulus elicited a measurable response.

\section{P50 Suppression Paradigm}

As summarized in Table 2, there was a significant main effect of stimulus type (conditioning $v s$ test stimulus) $\left(\mathrm{F}(1,20)=44.83, p<0.001, \eta_{\mathrm{p}}^{2}=0.69\right)$, indicating the occurrence of P50 suppression. Moreover, the interaction between stimulus type and group was significant $\left(\mathrm{F}(1,20)=5.27, p<0.05, \eta_{\mathrm{p}}^{2}=0.21\right)$. Fisher's LSD post hoc revealed that the amplitude in the placebo condition to the test $(p<0.05)$ but not to the conditioning $(p=0.97)$ stimulus was different between the two groups. Therefore, the anticipated distinction of P50 suppression between the high and low group was due to differences in the amplitudes elicited by the test stimulus, rather than the conditioning stimulus. Although there was no main effect of treatment, nor was there a significant interaction between treatment and stimulus type, the three-way interaction between treatment, stimulus type, and group $(F(1,20)=9.8$, $\left.p<0.01, \eta_{\mathrm{p}}^{2}=0.33\right)$ was significant.

As forced by the splitting of the subject group into low and high P50 gaters, analysis of P50 suppression, as indexed by percent suppression, revealed a significant main effect of group $\left(\mathrm{F}(1,20)=18.6, p<0.001, \eta_{\mathrm{p}}^{2}=0.48\right)$. Although there was no significant main effect of treatment, the interaction between treatment and group attained significance $\left(\mathrm{F}(1,20)=24.7, p<0.001, \eta_{\mathrm{p}}^{2}=0.55\right)$ (Figure 2), indicating the treatment effects differed between the two groups. Examination of the influence of test order revealed neither a significant main effect of test order nor any interactions with the other factors (group, treatment). Pearson correlations revealed no relationship between the absolute dose of haloperidol administered and change in P50 suppression.

There were no significant correlations among any of the parameters assessed (\%suppression, \%startle habituation, startle amplitudes, P50 amplitudes, P50 latencies) between the two gating paradigms (PPI and P50 suppression), either within or between the two treatment conditions. There was an overlap of five subjects $(26 \%)$ for the high ${ }_{\mathrm{PPI}}-$ high $_{\mathrm{P} 50}$ group combination and of seven subjects $(37 \%)$ for the

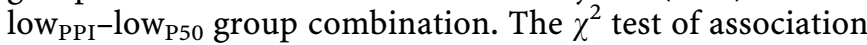
revealed no significance $(p=0.26)$.

\section{Neuropsychological Testing}

The results of CANTAB testing with respect to the PPI group formation are summarized in Table 3. Strategy in the SWM task was significantly better in the high than in the low PPI group $\left(\mathrm{F}(1,21)=7.82, p<0.05, \eta_{\mathrm{p}}^{2}=0.27\right)$. Moreover, Pearson correlation analysis revealed a significant correlation between strategy score and \%PPI at SOA60 in the placebo condition $(\mathrm{R}=-0.65, p<0.0008)$, indicating the presence of superior strategy formation in subjects with high PPI values (Figure 3). In the SOC task mean moves to solve the problem $\left(\mathrm{F}(1,21)=5.49, p<0.05, \eta_{\mathrm{p}}^{2}=0.21\right)$ and problems solved in minimum moves $(\mathrm{F}(1,21)=5.14$, $\left.p<0.05, \quad \eta_{\mathrm{p}}^{2}=0.20\right)$ were lower and mean subsequent thinking time $\left(\mathrm{F}(1,21)=6.18, p<0.05, \eta_{\mathrm{p}}^{2}=0.23\right)$ was shorter in the high PPI group. In the other CANTAB tasks no difference was found with respect to the low and high PPI group. Treatment with haloperidol impaired SWM performance as revealed by higher error rates $(\mathrm{F}(1,21)=12.26$, $p<0.01, \quad \eta_{\mathrm{p}}^{2}=0.37 \quad$ (between errors); $\mathrm{F}(1,21)=11.06$, 
Table 2 Sensory Gating Characteristics of Low and High Gating Groups Receiving Treatment with Placebo and Haloperidol

\begin{tabular}{|c|c|c|c|c|c|c|c|c|c|c|c|c|c|c|}
\hline \multirow[b]{3}{*}{ Electrophysiology } & \multicolumn{4}{|c|}{ Placebo } & \multicolumn{4}{|c|}{ Haloperidol } & & & & & & \\
\hline & \multicolumn{2}{|c|}{$\begin{array}{l}\text { Low group } \\
(n=I I / I I)\end{array}$} & \multicolumn{2}{|c|}{$\begin{array}{l}\text { High group } \\
(n=12 / I I)\end{array}$} & \multicolumn{2}{|c|}{$\begin{array}{l}\text { Low group } \\
(n=I I / I I)\end{array}$} & \multicolumn{2}{|c|}{$\begin{array}{l}\text { High group } \\
(n=I 2 / I I)\end{array}$} & \multicolumn{2}{|c|}{$\begin{array}{l}\text { Main effect of } \\
\text { group }\end{array}$} & \multicolumn{2}{|c|}{$\begin{array}{l}\text { Main effect of } \\
\text { treatment }\end{array}$} & \multicolumn{2}{|c|}{$\begin{array}{c}\text { Group } \times \text { treatment } \\
\text { interaction }\end{array}$} \\
\hline & Mean & SE & Mean & SE & Mean & SE & Mean & SE & $\mathbf{F}$ & $p$ & $\mathbf{F}$ & $p$ & $\mathbf{F}$ & $p$ \\
\hline \multicolumn{15}{|l|}{ PPI paradigm } \\
\hline Startle amplitude $(\mu \vee)^{a}$ & & & & & & & & & 1.62 & 0.22 & 0.36 & 0.56 & 1.50 & 0.23 \\
\hline Block I & 165.96 & 26.81 & 142.83 & 26.23 & 198.19 & 40.30 & 131.01 & 20.27 & & & & & & \\
\hline Block 2 & 113.37 & 23.92 & 101.37 & 20.92 & 145.53 & 31.86 & 91.43 & 13.79 & & & & & & \\
\hline Block 3 & 111.83 & 22.48 & 79.51 & 17.38 & 122.62 & 35.56 & 75.52 & 13.03 & & & & & & \\
\hline Prepulse reactivity $(\mu \vee)^{\mathrm{b}}$ & & & & & & & & & 3.50 & 0.08 & 0.82 & 0.38 & 0.05 & 0.82 \\
\hline Nonstimulus & 4.37 & 1.04 & 2.21 & 0.18 & 3.92 & 0.39 & 3.18 & 0.37 & & & & & & \\
\hline SOA $240 \mathrm{~ms}$ & 5.95 & 1.36 & 3.78 & 0.77 & 5.15 & 0.97 & 4.10 & 0.64 & & & & & & \\
\hline SOA $2000 \mathrm{~ms}$ & 4.67 & 0.98 & 3.49 & 0.50 & 7.01 & 1.94 & 4.01 & 0.81 & & & & & & \\
\hline Habituation (\%) & 33.83 & 7.52 & 38.94 & 9.49 & 39.64 & 6.17 & 38.22 & 9.20 & 0.05 & 0.84 & 0.10 & 0.75 & 0.17 & 0.69 \\
\hline Sensitization (\%) & 79.05 & 9.35 & 79.03 & 5.82 & 105.27 & 11.17 & 87.79 & 11.58 & 1.06 & 0.31 & 2.61 & 0.12 & 0.65 & 0.43 \\
\hline \multicolumn{15}{|l|}{ P50 suppression paradigm } \\
\hline Amplitudes $(\mu \bigvee)^{c}$ & & & & & & & & & 1.58 & 0.2 & 0.76 & 0.39 & 1.41 & 0.25 \\
\hline Conditioning stimulus & 1.31 & 0.27 & 1.32 & 0.24 & 1.25 & 0.29 & 1.08 & 0.19 & & & & & & \\
\hline Test stimulus & 1.07 & 0.24 & 0.15 & 0.03 & 0.62 & 0.17 & 0.47 & 0.13 & & & & & & \\
\hline Latency $(\mathrm{ms})^{\mathrm{d}}$ & & & & & & & & & 0.52 & 0.48 & 0.70 & 0.41 & 2.33 & 0.14 \\
\hline Conditioning stimulus & 61.00 & 2.12 & 57.91 & 1.05 & 59.91 & 1.83 & 59.09 & 1.90 & & & & & & \\
\hline Test stimulus & 59.82 & 0.97 & 56.73 & 1.80 & 59.18 & 1.84 & 61.45 & 1.50 & & & & & & \\
\hline
\end{tabular}

Abbreviations: PPI, prepulse inhibition; SOA, stimulus onset asynchrony.

a Repeated measures ANOVA including factor 'block'. Significant main effect of block $(F(2,42)=31.58, p<0.00 \mathrm{I})$.

'Repeated measures ANOVA including factor 'trial type'. Significant main effect of trial type $(F(2,42)=4.99, p<0.05)$

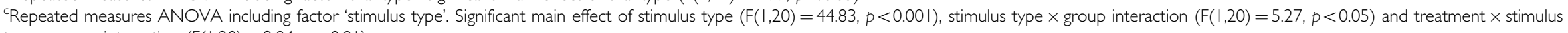
type $\times$ group interaction $(F(I, 20)=9.84, p<0.01)$.

'Repeated measures ANOVA including factor 'stimulus type'. 


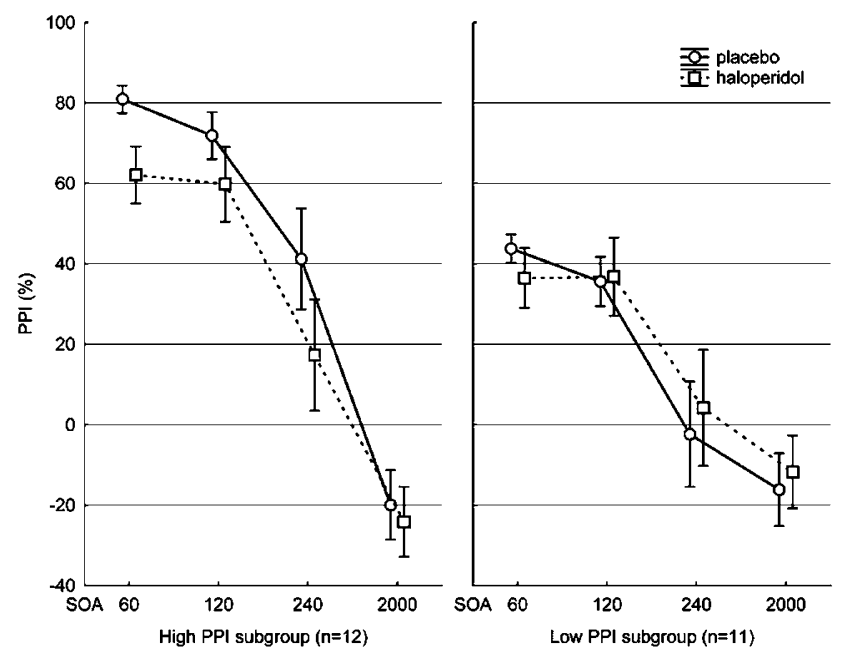

Figure I Percentage PPI at the four prepulse-pulse conditions (SOA: $60,120,240$, and $2000 \mathrm{~ms}$ ) in the low and the high PPI subgroups during placebo $(O)$ and haloperidol $(\square)$ treatment. Error bars refer to $\pm \mathrm{SE}$.

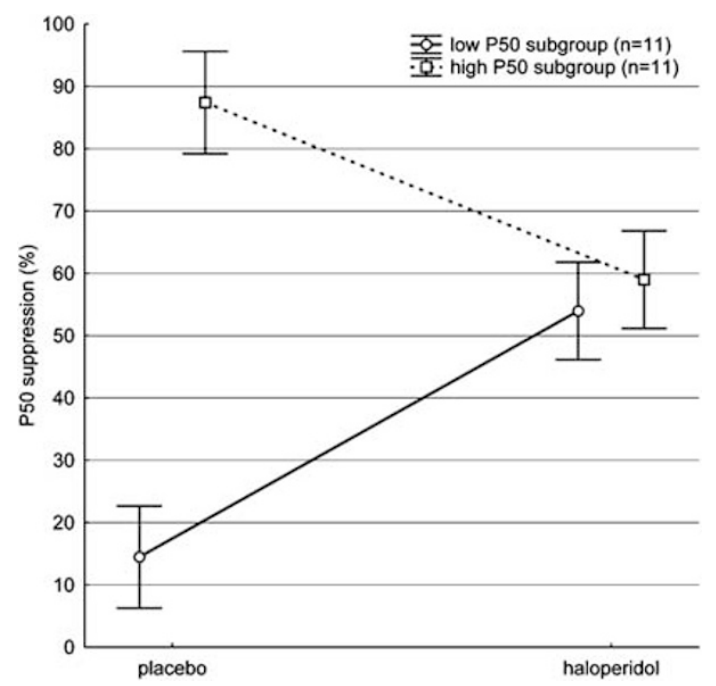

Figure 2 Percentage P50 suppression in the low $(\bigcirc)$ and the high $(\square)$ P50 subgroups during placebo and haloperidol treatment. Error bars refer to \pm SE.

$p<0.01, \eta_{\mathrm{p}}^{2}=0.35$ (total errors)) and by reduced strategy formation $\left(\mathrm{F}(1,21)=7.76, p<0.05, \eta_{\mathrm{p}}^{2}=0.27\right)$ in the SWM task. Although response latency in the SRM task $\left(\mathrm{F}(1,21)=4.74, p<0.05, \eta_{\mathrm{p}}^{2}=0.18\right)$ and initial thinking time in the SOC task $\left(\mathrm{F}(1,21)=5.98, p<0.05, \eta_{\mathrm{p}}^{2}=0.22\right)$ were reduced by haloperidol, there was no effect of the treatment on the general accuracy in those tasks. Main effects for difficulty were significant in the SOC and SWM task (see Table 3).

A corresponding analysis of the CANTAB data was conducted with respect to the grouping by P50 performance. The high and low P50 suppression subjects did not significantly differ in cognitive performance in any of the CANTAB tests. The main effects of haloperidol treatment on CANTAB scores were almost identical in the P50 group as in the PPI group, as expected due to the near identity of the two groups; haloperidol increased the error rates $\left(\mathrm{F}(1,20)=9.38, \quad p<0.01, \quad \eta_{\mathrm{p}}^{2}=0.32 \quad\right.$ (between errors); $\mathrm{F}(1,20)=8.8, p<0.01, \eta_{\mathrm{p}}^{2}=0.31$ (total errors)), and reduced the strategy score $\left(\mathrm{F}(1,20)=5.56, p<0.05, \eta_{\mathrm{p}}^{2}=0.22\right)$ in the SWM task. Furthermore, there was a reduction of the initial thinking time in the SOC task upon haloperidol treatment $\left(\mathrm{F}(1,20)=7.04, p<0.05, \eta_{\mathrm{p}}^{2}=0.26\right)$.

\section{DISCUSSION}

The present study was designed to test the hypothesis that the typical antipsychotic and dopamine $\mathrm{D}_{2}$-like receptor antagonist haloperidol differentially modulates PPI and P50 suppression in healthy human subjects stratified into groups with high and low gating performance. Haloperidol did not increase PPI in subjects exhibiting low placebo sensorimotor gating levels, but attenuated PPI in the group of subjects exhibiting high PPI in the placebo condition. The influence of haloperidol on P50 suppression depended critically on placebo P50 gating levels of the individual subject; while haloperidol increased P50 suppression in those subjects with low P50 suppression levels in the placebo condition, it reduced P50 suppression in individuals with high placebo P50 gating levels. Compared to individuals in the high PPI group, the group that exhibited low PPI levels had worse strategy formation in the SWM task. Furthermore, the strategy score correlated with \%PPI at SOA60 ms in the placebo condition. In the SOC task, the low PPI subjects needed more moves, solved fewer problems correctly within the minimum number of moves, and had increased subsequent thinking time.

\section{Prepulse Inhibition}

In contrast to results of our previous study (Vollenweider et al, 2006), which showed an enhancing effect of the atypical antipsychotic clozapine on PPI in subjects exhibiting low baseline sensorimotor gating levels, haloperidol failed to improve PPI in the low-performing group. This finding is in accordance with previous work investigating the effect of haloperidol on PPI in healthy volunteers (Kumari et al, 1998; Abduljawad et al, 1998, 1999; Liechti et al, 2001; Graham et al, 2001, 2002, 2004; Barrett et al, 2004; Oranje et al, 2004b). It is noteworthy that the haloperidol doses and SOA employed in most of these earlier studies were similar to the present study (Kumari et al, 1998; Abduljawad et al, 1999; Liechti et al, 2001; Graham et al, 2001, 2002, 2004; Barrett et al, 2004). Thus, it appears that stratification of normal subjects into low and high PPI performers did not reveal the predicted enhancement of PPI by haloperidol in normal subjects with relatively low PPI levels. This negative finding is in accordance with several studies in schizophrenia patients, which showed that atypical antipsychotic medication had no PPI-enhancing effect (Grillon et al, 1992; Kumari et al, 1999; Oranje et al, 2002b; Duncan et al, 2003a, b; Perry et al, 2002; Mackeprang et al, 2002). It should be noted that the healthy subjects in our earlier study (Vollenweider et al, 2006) had lower PPI levels $\left(\right.$ mean $\left._{\mathrm{SOA} 60}=8.8 \pm 3.3 \%\right)$ than did the low PPI group in the present study $\left(\operatorname{mean}_{\mathrm{SOA} 60}=43.8 \pm 13.8 \%\right)$. Thus, it remains possible that 
Table 3 Neuropsychological Characteristics of the Low and High PPI Subgroups Receiving Treatment with Placebo and Haloperidol

\begin{tabular}{|c|c|c|c|c|c|c|c|c|c|c|c|c|c|c|}
\hline \multirow[b]{3}{*}{ CANTAB tasks } & \multicolumn{4}{|c|}{ Placebo } & \multicolumn{4}{|c|}{ Haloperidol } & & & & & & \\
\hline & \multicolumn{2}{|c|}{$\begin{array}{l}\text { Low group } \\
\quad(n=I I)\end{array}$} & \multicolumn{2}{|c|}{$\begin{array}{l}\text { High group } \\
\quad(n=12)\end{array}$} & \multicolumn{2}{|c|}{$\begin{array}{l}\text { Low group } \\
(n=I I)\end{array}$} & \multicolumn{2}{|c|}{$\begin{array}{l}\text { High group } \\
\quad(n=12)\end{array}$} & \multicolumn{2}{|c|}{$\begin{array}{l}\text { Main effect of } \\
\text { group }\end{array}$} & \multicolumn{2}{|c|}{$\begin{array}{l}\text { Main effect of } \\
\text { treatment }\end{array}$} & \multicolumn{2}{|c|}{$\begin{array}{c}\text { Group } \times \text { treatment } \\
\text { interaction }\end{array}$} \\
\hline & Mean & SE & Mean & SE & Mean & SE & Mean & SE & $F(1,2 I)$ & $p$ & $F(I, 2 I)$ & $p$ & $F(1,2 I)$ & $p$ \\
\hline \multicolumn{15}{|l|}{$R V P$} \\
\hline$A^{\prime}$ & 0.94 & 0.01 & 0.95 & 0.01 & 0.94 & 0.02 & 0.95 & 0.01 & 1.01 & 0.33 & 0.02 & 0.9 & 0.05 & 0.83 \\
\hline Latency (ms) & 423.95 & 31.30 & 401.59 & $|5.4|$ & 420.44 & 24.40 & 404.19 & 15.73 & 0.46 & 0.5 & 0.00 & 0.97 & 0.05 & 0.81 \\
\hline Total hits & 20.27 & 1.47 & 21.75 & 0.92 & 20.18 & 1.65 & 22.00 & 1.22 & 0.96 & 0.34 & 0.01 & 0.92 & 0.04 & 0.83 \\
\hline \multicolumn{15}{|l|}{ ID/ED } \\
\hline EDS errors & 6.64 & 2.38 & 3.08 & 1.41 & 4.72 & 1.85 & 5.17 & 2.15 & 0.44 & 0.51 & $<0.01$ & 0.95 & 1.72 & 0.20 \\
\hline Pre-ED errors & 8.55 & 1.92 & 7.75 & 1.69 & 9.82 & 3.08 & 5.25 & 0.49 & 1.90 & 0.18 & 0.10 & 0.76 & 0.91 & 0.35 \\
\hline Total errors (adjusted) & 18.55 & 4.41 & 12.08 & 2.19 & 18.36 & 5.13 & 13.75 & 3.91 & 1.40 & 0.25 & 0.06 & 0.82 & 0.09 & 0.77 \\
\hline Total trials (adjusted) & 83.36 & 8.04 & 71.83 & 4.14 & 84.00 & 10.68 & 73.17 & 6.62 & 1.60 & 0.23 & 0.03 & 0.87 & $<0.01$ & 0.95 \\
\hline \multicolumn{15}{|l|}{ PRM } \\
\hline Latency (ms) & 1663.35 & 74.68 & 1553.79 & 49.74 & 1653.73 & 91.84 & 1566.87 & 51.92 & 1.53 & 0.23 & 0.00 & 0.97 & 0.04 & 0.83 \\
\hline Correct (\%) & 93.56 & 2.66 & 97.22 & 1.18 & 89.39 & 3.78 & 94.10 & 2.38 & 1.82 & 0.19 & 2.29 & 0.08 & 0.07 & 0.80 \\
\hline \multicolumn{15}{|l|}{ SRM } \\
\hline Latency (ms) & 1822.73 & 148.17 & 1799.49 & 203.77 & 1591.24 & 81.88 & 1591.15 & 120.63 & $<0.01$ & 0.95 & 4.74 & $<0.05$ & 0.01 & 0.90 \\
\hline Correct (\%) & 84.09 & 2.51 & 88.33 & 3.04 & 81.82 & 3.11 & 82.50 & 3.72 & 0.45 & 0.51 & 2.51 & 0.13 & 0.49 & 0.49 \\
\hline \multicolumn{15}{|l|}{ SWM } \\
\hline Between errors ${ }^{a}$ & & & & & & & & & 2.13 & 0.16 & 12.26 & $<0.01$ & 0.87 & 0.36 \\
\hline Difficulty level I & 0.36 & 0.28 & 0.08 & 0.08 & 0.64 & 0.34 & 0.17 & 0.17 & & & & & & \\
\hline Difficulty level 2 & 2.73 & 1.09 & 0.67 & 0.40 & 2.55 & 1.22 & 1.75 & 0.75 & & & & & & \\
\hline Difficulty level 3 & 5.82 & 1.59 & 2.08 & 0.95 & 10.45 & 2.39 & 9.08 & 1.81 & & & & & & \\
\hline Strategy & 28.82 & 1.31 & 22.58 & 0.84 & 29.91 & 1.87 & 26.67 & 1.33 & 7.82 & $<0.05$ & 7.76 & $<0.05$ & 2.60 & 0.12 \\
\hline Total errors & 9.36 & 2.84 & 2.83 & 1.06 & 13.64 & 3.40 & 11.08 & 2.38 & 2.26 & 0.15 & 11.06 & $<0.01$ & 1.20 & 0.30 \\
\hline \multicolumn{15}{|l|}{ SOC } \\
\hline Initial thinking time $(\mathrm{ms})^{\mathrm{b}}$ & & & & & & & & & 2.82 & 0.11 & 5.98 & $<0.05$ & 2.66 & 0.12 \\
\hline Difficulty level I & 1582.36 & 265.74 & |666.21 & 243.74 & 1492.09 & 310.65 & 1533.42 & 149.83 & & & & & & \\
\hline Difficulty level 2 & 7016.36 & 2897.70 & 2635.79 & 290.22 & 3450.18 & 670.99 & 2939.42 & 295.86 & & & & & & \\
\hline Difficulty level 3 & | 4757.55 & 3346.49 & 7299.08 & 895.62 & III52.32 & |87|.20 & 7158.40 & 2129.25 & & & & & & \\
\hline Difficulty level 4 & | 5744.34 & 3779.05 & 11221.29 & 1822.70 & 10057.43 & 2509.84 & 8603.81 & 848.11 & & & & & & \\
\hline
\end{tabular}


Table 3 Continued

\begin{tabular}{|c|c|c|c|c|c|c|c|c|c|c|c|c|c|c|}
\hline \multirow[b]{3}{*}{ CANTAB tasks } & \multicolumn{4}{|c|}{ Placebo } & \multicolumn{4}{|c|}{ Haloperidol } & & & & & & \\
\hline & \multicolumn{2}{|c|}{$\begin{array}{l}\text { Low group } \\
\quad(n=I I)\end{array}$} & \multicolumn{2}{|c|}{$\begin{array}{l}\text { High group } \\
\quad(n=12)\end{array}$} & \multicolumn{2}{|c|}{$\begin{array}{l}\text { Low group } \\
\quad(n=I I)\end{array}$} & \multicolumn{2}{|c|}{$\begin{array}{l}\text { High group } \\
\quad(n=\mid 2)\end{array}$} & \multicolumn{2}{|c|}{$\begin{array}{l}\text { Main effect of } \\
\text { group }\end{array}$} & \multicolumn{2}{|c|}{$\begin{array}{l}\text { Main effect of } \\
\text { treatment }\end{array}$} & \multicolumn{2}{|c|}{$\begin{array}{c}\text { Group } \times \text { treatment } \\
\text { interaction }\end{array}$} \\
\hline & Mean & SE & Mean & SE & Mean & SE & Mean & SE & $F(1,2 I)$ & $p$ & $F(1,2 I)$ & $p$ & $F(1,21)$ & $p$ \\
\hline Mean moves ${ }^{c}$ & & & & & & & & & 5.49 & $<0.05$ & 0.73 & 0.4 & 1.85 & 0.19 \\
\hline Difficulty level I & 2.00 & 0.00 & 2.00 & 0.00 & 2.00 & 0.00 & 2.00 & 0.00 & & & & & & \\
\hline Difficulty level 2 & 3.18 & 0.08 & 3.00 & 0.00 & 3.14 & 0.10 & 3.08 & 0.06 & & & & & & \\
\hline Difficulty level 3 & 4.66 & 0.22 & 4.23 & 0.16 & 5.07 & 0.26 & 4.48 & 0.25 & & & & & & \\
\hline Difficulty level 4 & 5.91 & 0.34 & 6.02 & 0.27 & 6.55 & 0.40 & 5.46 & 0.19 & & & & & & \\
\hline Subsequent thinking time $(\mathrm{ms})^{d}$ & & & & & & & & & 6.18 & $<0.05$ & 0.01 & 0.91 & 0.03 & 0.86 \\
\hline Difficulty level I & 163.23 & 116.10 & 0.00 & 0.00 & 89.20 & 48.87 & 174.98 & 121.77 & & & & & & \\
\hline Difficulty level 2 & 182.17 & 143.00 & 0.00 & 0.00 & 291.61 & 283.78 & 4.63 & 4.63 & & & & & & \\
\hline Difficulty level 3 & 379.32 & 163.33 & 269.37 & 184.00 & 675.93 & 176.41 & 221.81 & $|36.4|$ & & & & & & \\
\hline Difficulty level 4 & 656.23 & 206.18 & 408.50 & 118.49 & 409.73 & 101.72 & 255.42 & 83.33 & & & & & & \\
\hline $\begin{array}{l}\text { Problems solved in minimum } \\
\text { moves }\end{array}$ & 10.00 & 0.65 & 10.67 & 0.33 & 9.00 & 0.57 & 10.75 & 0.30 & 5.14 & $<0.05$ & 1.25 & 0.28 & 1.75 & 0.20 \\
\hline
\end{tabular}

moves

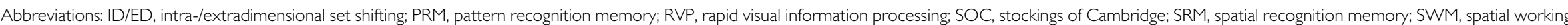
memory.

a Repeated measures ANOVA. Significant main effect of difficulty $\left(F(2,42)=40.0, p<0.001, \eta^{2}=0.66\right)$ and treatment $\times$ difficulty interaction $\left(F(2,42)=15.0, p<0.001, \eta^{2}=0.42\right)$.

${ }^{b}$ Repeated measures ANOVA. Significant main effect of difficulty $\left(F(3,63)=42.06, p<0.001, \eta^{2}=0.67\right)$.

${ }^{C}$ Repeated measures ANOVA. Significant main effect of difficulty $\left(F(3,63)=510.19, p<0.001, \eta^{2}=0.96\right)$ and diffuclty $\times$ group interaction $\left(F(3,63)=2.82, p<0.05, \eta^{2}=0.12\right)$.

${ }^{\mathrm{d}}$ Repeated measures ANOVA. Significant main effect of difficulty $\left(F(3,63)=7.9, p<0.00 I, \eta^{2}=0.27\right)$.

Values those are significant are in bold. 


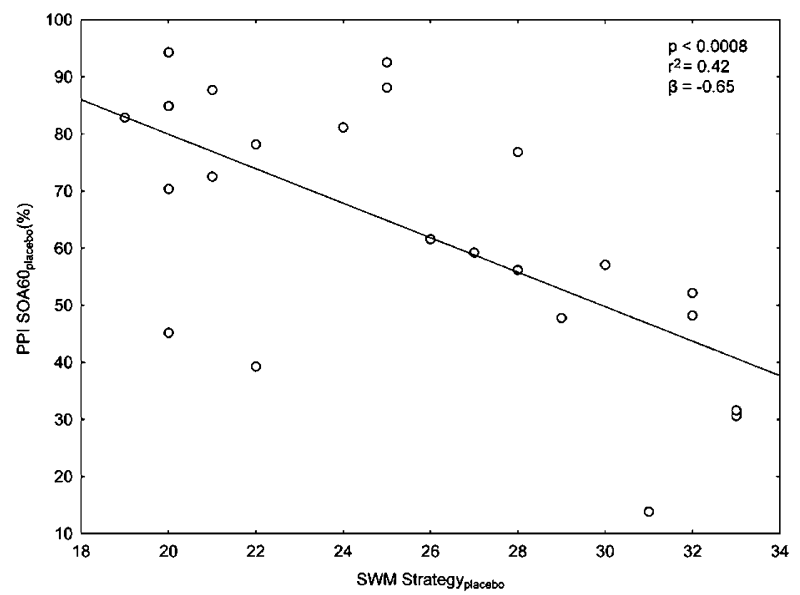

Figure 3 Correlation of percentage PPI at the SOA of $60 \mathrm{~ms}$ in the placebo condition and strategy score of the SWM task.

haloperidol might have enhanced PPI in subjects with extremely low PPI performance. Moreover, treatment with haloperidol significantly reduced PPI in subjects with high placebo \%PPI levels $\left(\right.$ mean $\left._{\text {SOA60 }}=80.9 \pm 9.6 \%\right)$. This finding is in accordance with two other studies reporting a haloperidol-induced reduction of \%PPI in subjects with comparable high baseline PPI performance at around $70 \%$ (Abduljawad et al, 1998; Oranje et al, 2004b). In addition, a number of studies (Kumari et al, 1998; Abduljawad et al, 1999; Liechti et al, 2001; Graham et al, 2001, 2002, 2004) found no effects of haloperidol on PPI in subjects expressing lower baseline PPI levels (40-60\%). Therefore, we can conclude that the effect of haloperidol on PPI is dependent on individuals' baseline gating levels. In contrast to the present findings with haloperidol, the mixed 5HT/ $\mathrm{D}_{2}$ receptor antagonists/antipsychotics clozapine (Vollenweider et al, 2006) and quetiapine (Swerdlow et al, 2006) have been reported to increase PPI in subjects exhibiting relatively low PPI levels. We speculate that the somewhat discrepant results between PPI studies using typical and atypical neuroleptics may indicate that serotonergic in addition to dopaminergic mechanisms may contribute to the modulation of PPI in clinically unaffected healthy subjects with low PPI levels.

\section{P50 Suppression}

Results of the present study show an enhancing effect of haloperidol on P50 suppression in subjects exhibiting low placebo suppression levels and an opposite (disruptive) effect in individuals showing high P50 suppression performance in the placebo condition. In contrast to this finding in healthy human individuals, in schizophrenia patients - although showing characteristically poor P50 suppression levels - typical antipsychotics such as haloperidol do not have an enhancing effect on P50 gating. Thus, dopamine $\mathrm{D}_{2}$ receptor antagonism alone seems insufficient to normalize P50 gating in schizophrenia patients, in contrast to effects seen in healthy subjects with low P50 suppression levels. Indeed, several earlier studies have shown that schizophrenia patients treated with typical antipsychotic medication exhibited significantly less P50 suppression than did patients receiving atypical antipsychotics (Light et al, 2000; Becker et al, 2004; Adler et al, 2004). Specifically, patients receiving clozapine (Tandon and Jibson, 2003; Adler et al, 2004) or olanzapine (Berg and Balaban, 1999) had superior suppression levels relative to those treated with typical antipsychotic medication. Moreover, Nagamoto et al (1996) reported that schizophrenia patients, who therapeutically responded to clozapine after 1 month of treatment also showed enhanced P50 suppression levels. Arango et al (2003) showed that 3 months' treatment with haloperidol did not result in an enhancement in P50 suppression. However, in that same study, treatment with the atypical antipsychotic olanzapine also failed to elevate P50 gating.

In contrast to the preponderance of studies of P50 suppression in patients with schizophrenia treated with typical neuroleptics, we found that haloperidol perturbed P50 suppression in healthy volunteers. To our knowledge no earlier studies have shown an effect of typical antipsychotic medication, specifically haloperidol, on P50 suppression, either in healthy volunteers or in schizophrenia patients. In view of this discrepancy, the question arises as to the extent of the involvement of dopamine neurotransmission in the regulation of P50 gating. Dopaminergic involvement in P50 suppression has been examined in several human and animal studies. For example, Damphetamine, an indirect dopaminergic and noradrenergic agonist, disrupts P50 suppression in healthy volunteers (Light et al, 1999), indicating that potentiation of catecholamine neurotransmission interferes with P50 gating. Animal models of N50 suppression, the rodent analogue of P50 in humans, also denoted as N40, have also implicated monoaminergic neurotransmitter systems in the modulation of P50 suppression. As in humans, acute D-amphetamine reduced gating of the N40 component in rodents (Adler et al, 1986; de Bruin et al, 1999). Thus, Adler et al (1986) conclude that 'catecholamines have significant modulatory effects on the gating, amplitude, and latency of P50 in humans and rats.' An amphetamine-induced increase specifically in noradrenergic transmission may mediate disruption of P50 suppression, since yohimbine, an $\alpha_{2}$ receptor antagonist that enhances the release of noradrenaline by a presynaptic mechanism, also disrupts P50 suppression in humans (Adler et al, 1994) and N40 suppression in animals (Stevens et al, 1993). Stevens et al (1993) conclude that a yohimbine-induced increase in endogenous noradrenergic tone resulted in disrupted sensory gating. This disruption could not be reversed by the $\mathrm{D}_{1}$ antagonist SCH 23390. Furthermore, Oranje et al (2004a) showed that the dopamine precursor L-dopa and the $\mathrm{D}_{2}$ receptor agonist bromocriptine both reduced the amplitudes of the P50 component evoked by the conditioning and the test stimuli equally, consequently not changing P50 suppression per se, providing further evidence that noradrenaline is more important than dopamine in the regulation of P50 suppression.

Taken together, the results of studies investigating monoaminergic influence in the regulation of P50 suppression and the findings that typical antipsychotic medication does not enhance P50 gating in patients call the putative role of dopamine in the modulation of P50 suppression into question. This scenario stands in contrast to our present findings, which demonstrated an elevation or disruption of 
P50 suppression by haloperidol, depending on the individual baseline P50 gating levels. In support of our present results, Adler et al (1986) demonstrated that the effect of haloperidol on N50 gating in rats depended highly on the initial state of individual animals; N50 suppression in those rats with high baseline suppression levels was unaffected by haloperidol, but was greatly enhanced by haloperidol in those rats showing consistently poor suppression values. Furthermore, Adler et al (1986) demonstrated that the disruptive effect of D-amphetamine on P50 gating could be reversed by haloperidol. Moreover, Oranje et al (2002a) found a disruptive effect of haloperidol and ketamine combined treatment on P50 suppression in humans, whereas the administration of ketamine alone was without effect. However the study by Adler et al (1986) was based on a small number of animals, while the study of Oranje et al (2002a) lacked a haloperidol-only condition, and so cannot be directly compared with the present design.

We speculate that the finding of the differential impact of typical antipsychotic medication on P50 suppression between schizophrenia patients and the present results in healthy volunteers might reflect unequal contributions of dopamine $\mathrm{D}_{2}$ receptors in the modulation of P50 gating between patients with schizophrenia and healthy volunteers. There is some precedent for such a distinction; studies involving patients with schizophrenia or bipolar disorder revealed that whereas P50 suppression deficits in bipolar patients are normalized by treatment with (typical) neuroleptics and lithium carbonate, there was no such normalization in the schizophrenia patient group (Franks et al, 1983; Adler et al, 1990). Furthermore, the correlation between P50 suppression and the severity of psychosis (Baker et al, 1987), and the finding that disrupted P50 suppression occurs during acute mania, but returns to normal values with abatement of the acute psychosis (Franks et al, 1983), indicates that reduced P50 suppression is state dependent in bipolar disorder (Franks et al, 1983; Baker et al, 1987; Adler et al, 1990). In contrast, disrupted P50 gating in schizophrenia spectrum disorder seems to reflect a trait deficit. Thus, our results in healthy volunteers add to what is already known about differences in P50 suppression among psychiatric conditions (Baker et al, 1987; Franks et al, 1983; Adler et al, 1990).

In line with previous studies that investigated the relationship between PPI and P50 suppression in healthy volunteers (Schwarzkopf et al, 1993; Oranje et al, 2006; Brenner et al, 2004; Light and Braff, 2001), we did not find any significant correlations between these two gating paradigms. Although in the present study PPI and P50 suppression were assessed in separate but immediately successive recording sessions, also no direct relationship has been found in studies which measured PPI and P50 suppression in a single recording session (Light and Braff 2001; Brenner et al, 2004; Oranje et al, 2006). However, Oranje et al (1999) reported a significant positive correlation between PPI and P50 suppression early in testing, when habituation of the startle reflex is taking place. Furthermore, Braff et al (2006) also reported weak positive correlation between the two measures of gating. Although there was an overlap of seven subjects (37\%) for the low $\mathrm{PPI}-\mathrm{low}_{\mathrm{P} 50}$ group combination in the present study, the $\chi^{2}$ test of association did not reach statistical significance.

\section{Relationship Between Neuropsychological Performance and Prepulse Inhibition}

As shown in Table 2, subjects with low and high PPI differed significantly in the SWM and planning task (SOC) of the CANTAB. High PPI levels predicted superior strategy formation and execution times. In particular, we found a correlation between the individuals' skill to form an appropriate search strategy in the SWM task and the magnitude of PPI (see Figure 3). In the SOC task, subjects with low PPI performance had prolonged subsequent thinking times, which may reflect a tendency to act before the strategy is fully formed, or may reveal the formation of less efficient strategies. Furthermore, the low PPI subjects required more moves per problem and consequently solved fewer problems in the minimum number of moves. A very similar pattern of results has been found recently in healthy volunteers (Bitsios et al, 2006; Giakoumaki et al, 2006), leading Bitsios et al (2006) to conclude that improved early information processing, as indexed by high PPI levels, is associated with superior abilities in strategy formation and execution times.

With respect to the present findings, it is of great importance that the performance in the SWM and SOC tasks relies on the integrity and efficiency of prefrontal cortical function. Patients with frontal lobe lesions are impaired in their ability to form efficient search strategies in the SWM task (Owen and Downes, 1990; Owen et al, 1996). Moreover, Owen and Downes (1990) found that patients with frontal lobe damage required more moves to solve the problem, and also exhibited prolonged subsequent thinking time in the SOC task. Our finding that high and low PPI subjects differ in their performance of tasks involving the prefrontal cortex supports the putative role of the prefrontal cortex in the modulation of PPI, a claim which is consistent with previous animal and human studies (Hazlett et al, 1998; Hazlett and Buchsbaum, 2001; Zavitsanou et al, 1999; Bubser and Koch, 1994; Kumari et al, 2003).

\section{The Effect of Haloperidol on Neuropsychological Performance}

The overall performance in the SWM task was impaired by haloperidol, as indicated by reduced strategy formation and increased error rates. There is considerable evidence that mesotelencephalic dopamine systems play a crucial role in cognitive processes involving the prefrontal cortex. Brozoski et al (1979) demonstrated that 6-hydroxydopamine lesions of the prefrontal cortex in rhesus monkeys impaired performance in a visuospatial delay task (delayed response task) to almost the same extent as was produced by surgical ablation of the same cortical area. Moreover, the reduced performance was reversed by dopamine receptor agonists. A number of more recent studies have shown that mainly dopamine $D_{1}$, but not $D_{2}$, receptors are involved in the modulation of tasks relying on intact prefrontal cortical functioning (Sawaguchi and Goldman-Rakic, 1991, 1994; Williams and Goldman-Rakic, 1995; Goldman-Rakic, 1996; Castner et al, 2000). Moreover, $\mathrm{D}_{1}$ receptor density exceeds $\mathrm{D}_{2}$ density by a factor of 10-20 in animal (Camps et al, 1990; Lidow et al, 1991) and human (De et al, 1988) cerebral cortex. However, there is evidence that cortical $\mathrm{D}_{2}$ receptors 
are nonetheless involved in working memory performance. Findings in healthy volunteers showed that haloperidol impaired performance in the SWM task (McCartan et al, 2001). Moreover, the $D_{2}$ antagonist sulpiride impaired in some (Mehta et al, 1999, 2004) but not in all (Mehta et al, 2003, 2005) studies working memory performance, while the $\mathrm{D}_{2}$ receptor agonist bromocriptine enhanced working memory performance in healthy humans (Mehta et al, 2001). In agreement with this finding in humans, systemic administration of the $D_{2}$ receptor agonist quinpirole in monkeys influenced working memory performance; while a low dose of quinpirole impaired working memory performance, higher doses led to an enhancement (Arnsten et al, 1995). Furthermore, Kimber et al (1997) demonstrated that bromocriptine either enhanced or impaired working memory capacity, depending on the baseline performance of the individual subject. Importantly, effects of $D_{2}$ receptor agents have only been observed after systemic administration but not after direct infusion into prefrontal cortex. In general, there seems not to be a linear relationship between working memory functions and dopaminergic mechanisms of the prefrontal cortex, but rather an inverted U-shape function, such that both low and high levels of dopamine are associated with impaired working memory performance (Murphy et al, 1996; Dreher et al, 2002; Robbins, 2005; Stewart and Plenz, 2006). Our finding that haloperidol impaired working memory performance as indexed by reduced strategy formation and enhanced error rates in the SWM task adds further evidence for the involvement of $D_{2}$ receptor family in working memory.

There are some limitations to the present study. First, a larger number of subjects would have been desirable, especially as they were stratified into subgroups. Although the statistical analysis was based to a large extent on a priori hypotheses, a large number of statistical comparisons were carried out. With a substantially larger sample size, one alternative would be to employ principal component analysis to reduce the number of critical variables. Second, a wider dose range of haloperidol would also be instrumental in investigating potential dose-dependent effects. In addition, the assessment of prolactin and homovanillic acid could have enriched the present study by providing additional measures of haloperidol's impact on dopaminerelated functions in individual subjects.

\section{CONCLUSION}

Our results show that effects of the typical antipsychotic haloperidol on sensorimotor gating as indexed by PPI and sensory gating as indexed by P50 suppression depend highly on the baseline gating state in healthy volunteers. This general finding stands in contrast with the available literature on gating in patients with schizophrenia, insofar our findings suggest a differential role of dopamine $\mathrm{D}_{2}$ receptors especially in the modulation of P50 suppression between schizophrenia patients and healthy volunteers. Moreover, we confirm the relationship between PPI and working memory performance in specific cognitive tasks relying on prefrontal cortical function, and show that haloperidol interfered in such prefrontal tasks in healthy subjects. The concomitant assessment of PPI and P50 suppression in healthy subjects with low gating levels may provide a translational model to elucidate the neuronal basis of PPI and P50 suppression deficits and its relation to cognition. Furthermore, this approach may provide a useful basis to assess the efficacy of novel treatments for patients with schizophrenia in proof of concept studies.

\section{ACKNOWLEDGEMENTS}

The present study was supported by the Zurich Psychiatric University Hospital and ETH Zurich. PAC received additional support by a grant from the Stiftung für Klinische Neuro-Psychiatrische Forschung, Berne, Switzerland. FXV was additionally supported by a NARSAD (The Mental Health Research Association) Independent Investigator Award, USA. BKY and JF received additional support from the NCCR: Neural Plasticity and Repair, Swiss National Science Foundation. MAG was supported by the US Veteran's Administration VISN 22 MIRECC and US NIH grant MH42228. We thank Dr Paul Cumming for critical reading of the manuscript.

\section{DISCLOSURE/CONFLICT OF INTEREST}

None of the authors has any competing interest to declare and the work was not supported by pharmaceutical industry grants. Dr Geyer holds an equity interest in San Diego Instruments.

\section{REFERENCES}

Abduljawad KA, Langley RW, Bradshaw CM, Szabadi E (1999). Effects of bromocriptine and haloperidol on prepulse inhibition: comparison of the acoustic startle eyeblink response and the N1/ P2 auditory-evoked response in man. J Psychopharmacol 13: 3-9. Abduljawad KAJ, Langley RW, Bradshaw CM, Szabadi E (1998). Effects of bromocriptine and haloperidol on prepulse inhibition of the acoustic startle response in man. J Psychopharmacol 12: 239-245.

Adler LE, Gerhardt GA, Franks R, Baker N, Nagamoto H, Drebing $\mathrm{C}$ et al (1990). Sensory physiology and catecholamines in schizophrenia and mania. Psychiatry Res 31: 297-309.

Adler LE, Hoffer L, Nagamoto HT, Waldo MC, Kisley MA, Giffith JM (1994). Yohimbine impairs P50 auditory sensory gating in normal subjects. Neuropsychopharmacology 10: 249-257.

Adler LE, Olincy A, Cawthra EM, McRae KA, Harris JG, Nagamoto HT et al (2004). Varied effects of atypical neuroleptics on P50 auditory gating in schizophrenia patients. Am J Psychiatry 161: 1822-1828.

Adler LE, Pachtman E, Franks RD, Pecevich M, Waldo MC, Freedman R (1982). Neurophysiological evidence for a defect in neuronal mechanisms involved in sensory gating in schizophrenia. Biol Psychiatry 17: 639-654.

Adler LE, Rose G, Freedman R (1986). Neurophysiological studies of sensory gating in rats: effects of amphetamine, phencyclidine, and haloperidol. Biol Psychiatry 21: 787-798.

Arango C, Summerfelt A, Buchanan RW (2003). Olanzapine effects on auditory sensory gating in schizophrenia. Am J Psychiatry 160: 2066-2068.

Arnsten AF, Cai JX, Steere JC, Goldman-Rakic PS (1995). Dopamine D2 receptor mechanisms contribute to age-related cognitive decline: the effects of quinpirole on memory and motor performance in monkeys. J Neurosci 15: 3429-3439. 
Badcock JC, Michiel PT, Rock D (2005). Spatial working memory and planning ability: contrasts between schizophrenia and bipolar I disorder. Cortex 41: 753-763.

Baker N, Adler LE, Franks RD, Waldo M, Berry S, Nagamoto H et al (1987). Neurophysiological assessment of sensory gating in psychiatric inpatients: comparison between schizophrenia and other diagnoses. Biol Psychiatry 22: 603-617.

Barrett SL, Bell R, Watson D, King DJ (2004). Effects of amisulpride, risperidone and chlorpromazine on auditory and visual latent inhibition, prepulse inhibition, executive function and eye movements in healthy volunteers. J Psychopharmacol 18: $156-172$.

Becker J, Gomes I, Ghisolfi ES, Schuch A, Ramos FL, Ehlers JA et al (2004). Clozapine, but not typical antipsychotics, correct P50 suppression deficit in patients with schizophrenia. Clin Neurophysiol 115: 396-401.

Berg WK, Balaban MT (1999). Startle elicitation: stimulus parameters, recording techniques, and quantification. In: Dawson ME, Schell AM, Bohmelt AH (eds.) Startle Modification: Implications for Neuroscience, Cognitive Science and Clinical Science. Cambridge University Press: New York. pp 21-50.

Bitsios P, Giakoumaki SG, Theou K, Frangou S (2006). Increased prepulse inhibition of the acoustic startle response is associated with better strategy formation and execution times in healthy males. Neuropsychologia 44: 2494-2499.

Braff DL, Geyer MA, Swerdlow NR (2001). Human studies of prepulse inhibition of startle: normal subjects, patient groups, and pharmacological studies. Psychopharmacology (Berl) 156: 234-258.

Braff DL, Light GA (2005). The use of neurophysiological endophenotypes to understand the genetic basis of schizophrenia. Dialog Clin Neurosci 7: 125-135.

Braff DL, Light GA, Swerdlow NR (2006). Prepulse inhibition and P50 suppression are both deficient but not correlated in schizophrenia patients. Biol Psychiatry [E-pub ahead of print].

Braff DL, Stone C, Callaway E, Geyer MA, Glick I, Bali L (1978). Prestimulus effects on human startle reflex in normals and schizophrenics. Psychophysiology 15: 339-343.

Brenner CA, Edwards CR, Carroll CA, Kieffaber PD, Hetrick WP (2004). P50 and acoustic startle gating are not related in healthy participants. Psychophysiology 41: 702-708.

Brozoski TJ, Brown RM, Rosvold HE, Goldman PS (1979). Cognitive deficit caused by regional depletion of dopamine in prefrontal cortex of rhesus monkey. Science 205: 929-932.

Bubser M, Koch M (1994). Prepulse inhibition of the acoustic startle response of rats is reduced by 6-hydroxydopamine lesions of the medial prefrontal cortex. Psychopharmacology (Berl) 113: 487-492.

Cadenhead KS (2002). Vulnerability markers in the schizophrenia spectrum: implications for phenomenology, genetics, and the identification of the schizophrenia prodrome. Psychiatr Clin North Am 25: 837-853.

Cadenhead KS, Geyer MA, Braff DL (1993). Impaired startle prepulse inhibition and habituation in patients with schizotypal personality disorder. Am J Psychiatry 150: 1862-1869.

Cadenhead KS, Light GA, Geyer MA, Braff DL (2000). Sensory gating deficits assessed by the P50 event-related potential in subjects with schizotypal personality disorder. Am J Psychiatry 157: 55-59.

Cadenhead KS, Light GA, Geyer MA, McDowell JE, Braff DL (2002). Neurobiological measures of schizotypal personality disorder: defining an inhibitory endophenotype? Am J Psychiatry 159: 869-871.

Camps M, Kelly PH, Palacios JM (1990). Autoradiographic localization of dopamine D1 and D2 receptors in the brain of several mammalian species. J Neural Transm Gen Sect 80: 105-127.
Castner SA, Williams GV, Goldman-Rakic PS (2000). Reversal of antipsychotic-induced working memory deficits by short-term dopamine D1 receptor stimulation. Science 287: 2020-2022.

Clementz BA, Geyer MA, Braff DL (1998a). Multiple site evaluation of P50 suppression among schizophrenia and normal comparison subjects. Schizophr Res 30: 71-80.

Clementz BA, Geyer MA, Braff DL (1998b). Poor P50 suppression among schizophrenia patients and their first-degree biological relatives. Am J Psychiatry 155: 1691-1694.

de Bruin NM, Ellenbroek BA, Cools AR, Coenen AM, van Luijtelaar EL (1999). Differential effects of ketamine on gating of auditory evoked potentials and prepulse inhibition in rats. Psychopharmacology (Berl) 142: 9-17.

De KJ, Claeys A, De Backer JP, Ebinger G, Roels F, Vauquelin G (1988). Autoradiographic localization of D1 and D2 dopamine receptors in the human brain. Neurosci Lett 91: 142-147.

Dreher JC, Guigon E, Burnod Y (2002). A model of prefrontal cortex dopaminergic modulation during the delayed alternation task. J Cogn Neurosci 14: 853-865.

Duncan E, Szilagyi S, Schwartz M, Kunzova A, Negi S, Efferen T et al (2003a). Prepulse inhibition of acoustic startle in subjects with schizophrenia treated with olanzapine or haloperidol. Psychiatry Res 120: 1-12.

Duncan EJ, Szilagyi S, Efferen TR, Schwartz MP, Parwani A, Chakravorty $S$ et al (2003b). Effect of treatment status on prepulse inhibition of acoustic startle in schizophrenia. Psychopharmacology 167: 63-71.

Ellenbroek BA, van LG, Frenken M, Cools AR (1999). Sensory gating in rats: lack of correlation between auditory evoked potential gating and prepulse inhibition. Schizophr Bull 25: 777-788.

Franks RD, Adler LE, Waldo MC, Alpert J, Freedman R (1983). Neurophysiological studies of sensory gating in mania: comparison with schizophrenia. Biol Psychiatry 18: 989-1005.

Frost WN, Tian LM, Hoppe TA, Mongeluzi DL, Wang J (2003). A cellular mechanism for prepulse inhibition. Neuron 40: 991-1001.

Geyer MA, Krebs-Thomson K, Braff DL, Swerdlow NR (2001). Pharmacological studies of prepulse inhibition models of sensorimotor gating deficits in schizophrenia: a decade in review. Psychopharmacology (Berl) 156: 117-154.

Giakoumaki SG, Bitsios P, Frangou S (2006). The level of prepulse inhibition in healthy individuals may index cortical modulation of early information processing. Brain Res 1078: 168-170.

Goldman-Rakic PS (1996). The prefrontal landscape: implications of functional architecture for understanding human mentation and the central executive. Philos Trans R Soc Lond B Biol Sci 351: $1445-1453$.

Graham FK (1975). The more or less startling effects of weak prestimuli. Psychophysiology 12: 238-248.

Graham FK (1980). Neural mechanism of goal-directed behaviour learning. In: Thompson RF, Hicks VB, Shvyrkov VB (eds.) Control of Blink Reflex Excitability. Academic Press: New York. pp 511-519.

Graham FK (1992). Attention and information processing in infants and adults: perspectives from human and animal research. In: Campell BA, Hayne $\mathrm{H}$, Richardson $\mathrm{R}$ (eds). Attention: The Heartbeat, the Blink, and the Brain. Lawrence Erlbaum Associates: Hillsdale, NJ. pp 3-29.

Graham SJ, Langley RW, Balboa Verduzco AM, Bradshaw CM, Szabadi E (2002). Effects of ketanserin and haloperidol on prepulse inhibition of the acoustic startle (eyeblink) response and the N1/P2 auditory evoked response in man. J Psychopharmacol 16: 15-22.

Graham SJ, Langley RW, Bradshaw CM, Szabadi E (2001). Effects of haloperidol and clozapine on prepulse inhibition of the acoustic startle response and the N1/P2 auditory evoked potential in man. J Psychopharmacol 15: 243-250. 
Graham SJ, Scaife JC, Balboa Verduzco AM, Langley RW, Bradshaw CM, Szabadi E (2004). Effects of quetiapine and haloperidol on prepulse inhibition of the acoustic startle (eyeblink) response and the N1/P2 auditory evoked response in man. J Psychopharmacol 18: 173-180.

Grillon C, Ameli R, Charney DS, Krystal J, Braff DL (1992). Startle gating deficits occur across prepulse intensities in schizophrenic patients. Biol Psychiatry 32: 939-943.

Hamm AO, Weike AI, Schupp HT (2001). The effect of neuroleptic medication on prepulse inhibition in schizophrenia patients: current status and future issues. Psychopharmacology 156: 259-265.

Hazlett E, Buchsbaum M, Haznedar MM, Singer MB, Germans MK, Schnur DB et al (1998). Prefrontal cortex glucose metabolism and startle eyeblink modification abnormalities in unmedicated schizophrenia patients. Psychophysiology 35: 186-198.

Hazlett EA, Buchsbaum MS (2001). Sensorimotor gating deficits and hypofrontality in schizophrenia. Front Biosci 6: D1069-D1072.

Heaton HK (1981). A manual for the Wisconsin Card Sorting Test. Psychological Assessment Resources: Odessa, FL.

Hoffman HS, Ison JR (1980). Reflex modification in the domain of startle: I. Some empirical findings and their implications for how the nervous system processes sensory input. Psychol Rev 87: 175-189.

Hutton SB, Puri BK, Duncan L-J, Robbins TW, Barnes TRE, Joyce EM (1998). Executive function in first-episode schizophrenia. Psychol Med 28: 463-473.

Kimberg DY, D'Esposito M, Farah MJ (1997). Effects of bromocriptine on human subjects depend on working memory capacity. NeuroReport 8: 3581-3585.

Kumari V, Das M, Zachariah E, Ettinger U, Sharma T (2005). Reduced prepulse inhibition in unaffected siblings of schizophrenia patients. Psychophysiology 42: 588-594.

Kumari V, Gray JA, Geyer MA, ffytche D, Soni W, Mitterschiffthaler MT et al (2003). Neural correlates of tactile prepulse inhibition: a functional MRI study in normal and schizophrenic subjects. Psychiatry Res Neuroimaging 122: 99-113.

Kumari V, Mulligan OF, Cotter PA, Poon L, Toone BK, Checkley SA et al (1998). Effects of single oral administrations of haloperidol and d-amphetamine on prepulse inhibition of the acoustic startle reflex in healthy male volunteers. Behav Pharmacol 9: 567-576.

Kumari V, Sharma T (2002). Effects of typical and atypical antipsychotics on prepulse inhibition in schizophrenia: a critical evaluation of current evidence and directions for future research. Psychopharmacology 162: 97-101.

Kumari V, Soni W, Mathew VM, Sharma T (2000). Prepulse inhibition of the startle response in men with schizophrenia: effects of age of onset of illness, symptoms, and medication. Arch Gen Psychiatry 57: 609-614.

Kumari V, Soni W, Sharma T (1999). Normalization of information processing deficits in schizophrenia with clozapine. Am J Psychiatry 156: 1046-1051.

Kumari V, Soni W, Sharma T (2002). Prepulse inhibition of the startle response in risperidone-treated patients: comparison with typical antipsychotics. Schizophr Res 55: 139-146.

Lehrl S (1999). Mehrfachwahl-Wortschatz-Intelligenztest (MWT-B). Hogrefe: Göttingen.

Leumann L, Feldon J, Vollenweider FX, Ludewig K (2002). Effects of typical and atypical antipsychotics on prepulse inhibition and latent inhibition in chronic schizophrenia. Biol Psychiatry 52: 729-739.

Lidow MS, Goldman-Rakic PS, Gallager DW, Rakic P (1991). Distribution of dopaminergic receptors in the primate cerebral cortex: quantitative autoradiographic analysis using $\left[{ }^{3} \mathrm{H}\right]$ raclopride, $\left[{ }^{3} \mathrm{H}\right]$ spiperone and $\left[{ }^{3} \mathrm{H}\right] \mathrm{SCH} 23390$. Neuroscience 40: 657-671.
Liechti ME, Geyer MA, Hell D, Vollenweider FX (2001). Effects of MDMA on prepulse inhibition and habituation of startle in humans after pretreatment with citalopram, haloperidol, or ketanserin. Neuropsychopharmacology 24: 240-252.

Light GA, Braff DL (1999). Human and animal studies of schizophrenia-related gating deficits. Curr Psychiatry Rep 1: 31-40.

Light GA, Braff DL (2001). Measuring P50 suppression and prepulse inhibition in a single recording session. Am J Psychiatry 158: 2066-2068.

Light GA, Geyer MA, Clementz BA, Cadenhead KS, Braff DL (2000). Normal P50 suppression in schizophrenia patients treated with atypical antipsychotic medications. Am J Psychiatry 157: 767-771.

Light GA, Malaspina D, Geyer MA, Luber BM, Coleman EA, Sackeim HA et al (1999). Amphetamine disrupts P50 suppression in normal subjects. Biol Psychiatry 46: 990-996.

Mackeprang T, Kristiansen KT, Glenthoj BY (2002). Effects of antipsychotics on prepulse inhibition of the startle response in drug-naive schizophrenic patients. Biol Psychiatry 52: 863-873.

McCartan D, Bell R, Green JF, Campbell C, Trimble K, Pickering A et al (2001). The differential effects of chlorpromazine and haloperidol on latent inhibition in healthy volunteers. J Psychopharmacol 15: 96-104.

Mehta MA, Hinton EC, Montgomery AJ, Bantick RA, Grasby PM (2005). Sulpiride and mnemonic function: effects of a dopamine D2 receptor antagonist on working memory, emotional memory and long-term memory in healthy volunteers. J Psychopharmacol 19: 29-38.

Mehta MA, Manes FF, Magnolfi G, Sahakian BJ, Robbins TW (2004). Impaired set-shifting and dissociable effects on tests of spatial working memory following the dopamine D2 receptor antagonist sulpiride in human volunteers. Psychopharmacology (Berl) 176: 331-342.

Mehta MA, McGowan SW, Lawrence AD, Aitken MR, Montgomery AJ, Grasby PM (2003). Systemic sulpiride modulates striatal blood flow: relationships to spatial working memory and planning. Neuroimage 20: 1982-1994.

Mehta MA, Sahakian BJ, McKenna PJ, Robbins TW (1999). Systemic sulpiride in young adult volunteers simulates the profile of cognitive deficits in Parkinson's disease. Psychopharmacology (Berl) 146: 162-174.

Mehta MA, Swainson R, Ogilvie AD, Sahakian J, Robbins TW (2001). Improved short-term spatial memory but impaired reversal learning following the dopamine $\mathrm{D}(2)$ agonist bromocriptine in human volunteers. Psychopharmacology 159: 10-20.

Meincke U, Mörth D, Voss T, Thelen B, Geyer MA, GouzoulisMayfrank E (2004). Prepulse inhibition of the acoustically evoked startle reflex in patients with an acute schizophrenic psychosis-a longitudinal study. Eur Arch Psychiatry Clin Neuosci 254: 415-421.

Murphy BL, Arnsten AF, Jentsch JD, Roth RH (1996). Dopamine and spatial working memory in rats and monkeys: pharmacological reversal of stress-induced impairment. J Neurosci 16: 7768-7775.

Nagamoto HT, Adler LE, Hea RA, Griffith JM, McRae KA, Freedman R (1996). Gating of auditory P50 in schizophrenics: unique effects of clozapine. Biol Psychiatry 40: 181-188.

Nagamoto HT, Adler LE, Waldo MC, Freedman R (1989). Sensory gating in schizophrenics and normal controls: effects of changing stimulation interval. Biol Psychiatry 25: $549-561$

Oranje B, Geyer MA, Bocker KB, Leon KJ, Verbaten MN (2006). Prepulse inhibition and P50 suppression: commonalities and dissociations. Psychiatry Res 143: 147-158.

Oranje B, Gispen-De Wied CC, Verbaten MN, Kahn RS (2002a). Modulating sensory gating in healthy volunteers: the effects of ketamine and haloperidol. Biol Psychiatry 52: 887-895. 
Oranje B, Gispen-De Wied CC, Westenberg HG, Kemner C, Verbaten MN, Kahn RS (2004a). Increasing dopaminergic activity: effects of L-dopa and bromocriptine on human sensory gating. J Psychopharmacol 18: 388-394.

Oranje B, Kahn RS, Kemner C, Verbaten MN (2004b). Modulating sensorimotor gating in healthy volunteers: the effects of desipramine and haloperidol. Psychiatry Res 127: 195-205.

Oranje B, van Berckel BN, Kemner C, Van Ree JM, Kahn RS, Verbaten MN (1999). P50 suppression and prepulse inhibition of the startle reflex in humans: a correlational study. Biol Psychiatry 45: 883-890.

Oranje B, Van Oel CJ, Gispen-De Wied CC, Verbaten MN, Kahn RS (2002b). Effects of typical and atypical antipsychotics on the prepulse inhibition of the startle reflex in patients with schizophrenia. J Clin Psychopharmacol 22: 359-365.

Owen AM, Downes J (1990). Planning and spatial working memory following frontal lobe lesions in man. Neuropsychologia 28: 1021-1034.

Owen AM, Morris RG, Sahakian BJ, Polkey CE, Robbins TW (1996). Double dissociations of memory and executive functions in working memory tasks following frontal lobe excisions, temporal lobe excisions or amygdalo-hippocampectomy in man. Brain 119(Part 5): 1597-1615.

Perry W, Feifel D, Minassian A, Bhattacharjie I, Braff DL (2002). Information processing deficits in acutely psychotic schizophrenia patients medicated and unmedicated at the time of admission. Am J Psychiatry 159: 1375-1381.

Pirozzo S, Papinczak T, Glasziou P (2003). Whispered voice test for screening for hearing impairment in adults and children: systematic review. BMJ 327: 967.

Quednow BB, Wagner M, Westheide J, Beckmann K, Bliesener N, Maier W et al (2005). Sensorimotor gating and habituation of the startle response in schizophrenic patients randomly treated with amisulpride or olanzapine. Biol Psychiatry 59: 536-545.

Robbins TW (2005). Chemistry of the mind: neurochemical modulation of prefrontal cortical function. J Comp Neurol 493: 140-146.

Sawaguchi T, Goldman-Rakic PS (1991). D1 dopamine receptors in prefrontal cortex: involvement in working memory. Science 251: 947-951.

Sawaguchi T, Goldman-Rakic PS (1994). The role of D1-dopamine receptor in working memory: local injections of dopamine antagonists into the prefrontal cortex of rhesus monkeys performing an oculomotor delayed-response task. J Neurophysiol 71: 515-528.

Schwarzkopf SB, Lamberti JS, Smith DA (1993). Concurrent assessment of acoustic startle and auditory P50 evoked potential measures of sensory inhibition. Biol Psychiatry 33: 815-828.

Shallice T (1982). Specific impairments of planning. Philos Trans $R$ Soc Lond B Biol Sci 298: 199-209.

Stevens KE, Meltzer J, Rose GM (1993). Disruption of sensory gating by the alpha 2 selective noradrenergic antagonist yohimbine. Biol Psychiatry 33: 130-132.

Stewart CV, Plenz D (2006). Inverted-U profile of dopamineNMDA-mediated spontaneous avalanche recurrence in superficial layers of rat prefrontal cortex. J Neurosci 26: 8148-8159.

Swerdlow NR, Hartman PL, Auerbach PP (1996). Changes in sensorimotor inhibition across the menstrual cycle: implications for neuropsychiatric disorders. Biol Psychiatry 41: 452-460.

Swerdlow NR, Talledo J, Sutherland AN, Nagy D, Shoemaker JM (2006). Antipsychotic effects on prepulse inhibition in normal 'low gating' humans and rats. Neuropsychopharmacology 31: 2011-2021.

Tandon R, Jibson MD (2003). Safety and tolerability: how do second-generation atypical antipsychotics compare? Curr Psychosis Therap Rep 1: 1-7.

Vollenweider FX, Barro M, Csomor PA, Feldon J (2006). Clozapine enhances prepulse inhibition in healthy humans with low but not with high prepulse inhibition levels. Biol Psychiatry 60 597-603.

Weickert TW, Goldberg TE, Gold JM, Bigelow LB, Egan MF, Weinberger DR (2000). Cognitive impairments in patients with schizophrenia displaying preserved and compromised intellect. Arch Gen Psychiatry 57: 907-913.

Williams GV, Goldman-Rakic PS (1995). Modulation of memory fields by dopamine D1 receptors in prefrontal cortex. Nature 376: $572-575$.

Wittchen HU, Pfister H (1997). DIA-X-Interview. Swets Test Services: Frankfurt.

Zavitsanou K, Cranney J, Richardson R (1999). Dopamine antagonists in the orbital prefrontal cortex reduce prepulse inhibition of the acoustic startle reflex in the rat. Pharmacol Biochem Behav 63: 55-61. 